\title{
CONTEÚDOS HIPERMODAIS PARA FINS DE APRENDIZAGEM: USOS EM CONTEXTO PELOS ALUNOS
}

\author{
Eduardo S. Junqueira*
}

RESUMO: A análise dos usos de artefatos e conteúdos hipermodais pelos alunos, para fins de aprendizagem na modalidade do ensino a distância, indicou dois elementos-chave. A estrutura e a coesão dos conteúdos, identificados a partir de categorias estáveis de análise semiótica de materiais hipermodais, não determinaram o uso. Norteados por elementos culturais e por suas intenções, os alunos formularam práticas comunicativas que extrapolaram a dicotomia impresso/digital. Imprimiram os conteúdos disponibilizados na tela do computador e instituíram a centralidade do impresso para a aprendizagem, sem, no entanto, ignorar os conteúdos hipermodais. A partir do impresso, utilizaram tais conteúdos em "rede" e construíram trilhas de navegação e leitura coerentes, voltadas a fins de aprendizagem específicos. Indica-se a necessidade de processos flexíveis e com a participação dos usuários-alunos para a produção de conteúdos mais interativos e democráticos.

Palavras-chave: Hipermodalidade; Práticas Comunicativas; Aprendizagem.

\section{HYPERMODAL CONTENT TO LEARNING: STUDENT'S CONTEXTUALIZED USE}

ABSTRACT: The analysis of the use of hypermodal artifacts and content by distance learning students indicated two key elements. Content structure and cohesion, established by stable semiotic categories of hypermodal artifact's analysis, indicated that they have not determined the student's use. Guided by cultural elements and their own goals, students established communicative practices that extrapolated the print/digital dichotomy. The students printed the online content and established the centrality of the printing material for their learning without disregarding hypermodal content. From the printing material, they used content as "webs" and developed paths as they coherently navigated and read the materials. The study indicates the need to establish flexible, open to participation processes of content design aimed at the student's participation to produce more interactive and democratic content for the production of learning.

Keywords: Hypermodality; Communicative Practices; Learning.

\footnotetext{
* Doutor em Educação pela Michigan State University; Professor adjunto do Instituto Universidade Virtual da Universidade Federal do Ceará (UFC) e Professor do Programa de Pós-Graduação em Educação Brasileira da Universidade Federal do Ceará (UFC).E-mail: eduardoj@virtual.ufc.br
} 


\section{Introdução}

Recentemente tenho lidado com a difícil perspectiva que se coloca para os pesquisadores e educadores ao enfrentarem a questão do uso pedagógico de artefatos com conteúdos hipermodais no ensino a distância (EaD) na Universidade Aberta do Brasil (UAB), voltada a alunos de baixo nível de renda econômica e de regiões remotas do país. Como os alunos acessam e utilizam conteúdos hipermodais em seus processos de aprendizagem? Como experiências anteriores de aprendizagem interferem em tais acesso e uso? Como as rotinas e exigências institucionais atuam nesse processo de aprendizagem formal? Qual o papel do(s) contexto(s) em que vivem e da história de vida dos alunos nessas experiências?

Neste artigo, apresento ocorrências documentadas durante estudo realizado junto a alunos de um curso de graduação em dois pólos da $\mathrm{UAB}$, na região Nordeste. O tema e os dados aqui tratados se revelaram surpreendentes para mim, pois iniciei minha pesquisa mais interessado em observar ações de navegação e leitura hipermodal na tela do computador do que em me deter sobre as nuances dessas complexas experiências. As observações indicam que - a fim de "melhor estudar" - os alunos preferem imprimir os conteúdos curriculares disponibilizados em formato hipermodal pela instituição de ensino na internet. No entanto, a impressão de tais conteúdos não produziu uma ruptura com a navegação e a leitura hipermodal, mas conferiu-lhe novos contornos e ênfases.

Procurei dar sentido a alguns elementos relacionados a tal ocorrência a partir das proposições da "gramática" dos artefatos hipermodais de Lemke (2001; 2002), utilizadas na identificação dos elementos de estrutura e de coesão dos conteúdos hipermodais disponibilizados aos alunos. Baseei-me também nas teorizações sobre multimodalidade ${ }^{1}$ de Kress (2003), hipertextualidade de Marcuschi (2005) e práticas comunicativas de Hanks (1996) para contextualizar e dar sentido às ações dos alunos com os conteúdos. Busquei, dessa forma, contemplar o que me parecem ser dois elementos-chave da experiência com conteúdos hipermodais para a aprendizagem a distância - do artefato semiótico disponibilizado pela instituição de ensino e seu uso contextualizado pelos alunos. 


\section{Dados empíricos}

Trata-se de estudo na perspectiva etnográfica, em que se busca documentar e compreender as ações dos participantes a partir das perspectivas socioculturais deles (BOGDAN; BIKLEN, 2003). Para a coleta de dados, solicitei que os alunos utilizassem o ambiente virtual de aprendizagem (AVA) para realizar as atividades de estudo. O roteiro de navegação dos alunos (movimentos do mouse na tela, movimentos dentro da "Aula" e movimentos entre telas) foi documentado. Em seguida, solicitei que repetissem a mesma operação e, desta vez, pedi que explicassem suas ações. Fiz perguntas para esclarecimento sobre a navegação e o uso dos conteúdos, procurando compreender tais ocorrências. As observações e os diálogos constituíram o material de pesquisa analisado à luz do referencial teórico do estudo.

Dada a exiguidade de espaço, deterei-me na experiência de João (pseudônimo), por ser representativa de outros alunos de dois pólos da UAB (curso de licenciatura em Letras-Português), em que as observações e coleta de dados foram conduzidas. João já cursou dez disciplinas a distância, estando familiarizado com os conteúdos digitais disponibilizados pela instituição de ensino na interface web. À época da coleta de dados, a instituição não oferecia conteúdos impressos, indicando aos alunos que o estudo deveria ser realizado por meio dos conteúdos multimodais digitais disponibilizados no AVA.

Acompanhei João em duas sessões de estudos, em seu local de trabalho, depois de encerrado o expediente. Ao acessar a "Aula" (conjunto de páginas web com conteúdos curriculares multimodais no AVA), João verificou a extensão dos materiais exibidos na tela e checou a existência de atividades, web links e outros materiais hipertextuais e multimodais. Mas não acessou nem leu nenhum desses elementos. $\mathrm{O}$ aluno imprimiu os conteúdos exibidos na tela, assim como atividades e outros conteúdos disponibilizados na "Aula" (arquivos em formatos .doc ou .pdf), e reuniu todos esses materiais em uma "apostila". Disse que opta pela impressão porque "é muito ruim ler na tela do computador". Ele relatou que colegas de curso adotam procedimento semelhante e que fornece os materiais impressos para que eles façam cópias, já que muitos não têm acesso a uma impressora.

João não acessou nenhum dos outros elementos multimodais presentes no conteúdo da "Aula" exibidos na tela, como web links, mouse-over, 
tabela dinâmica, animações em Flash e vídeos (para exemplos, ver Figuras 1 e 2), porque, segundo ele, os conteúdos textuais desses objetos estão contidos no material impresso (com exceção dos vídeos). $\mathrm{O}$ aluno informou que teria se detido, no entanto, na leitura de animações que tivessem sido iniciadas automaticamente na tela, presentes em algumas "Aulas" (mas não na observada). Ele justificou: "o conteúdo da animação está impresso e o objetivo principal é ler o texto para aprender" e disse que "reconhece que a animação ajuda mais na aprendizagem do que o texto escrito".

Figura 1. Reprodução da tela (colorida, no original) mostra conteúdos da "Aula" contendo três links (textos destacados em cinza claro) não acessados por João.

Os conteúdos aparecem integralmente na versão impressa pelo aluno.

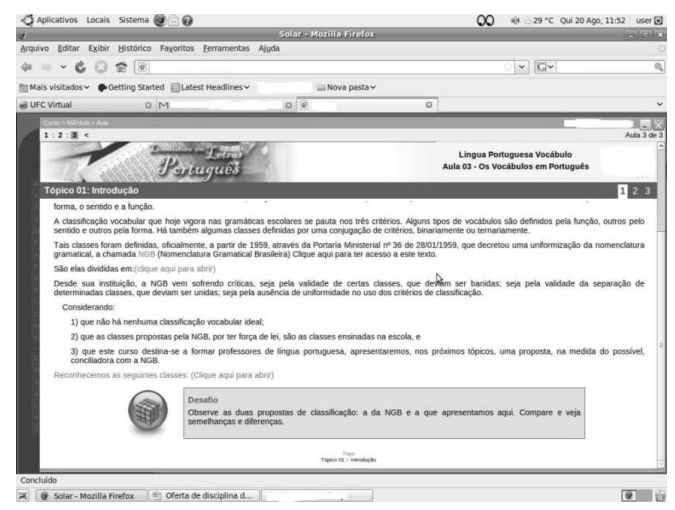

Figura 2. Reprodução da tela (colorida, no original) mostra o conteúdo textual e objeto animado na "Aula", não acessado pelo aluno na sessão observada.

Este conteúdo aparece da mesma forma na versão impressa utilizada por João para estudo.

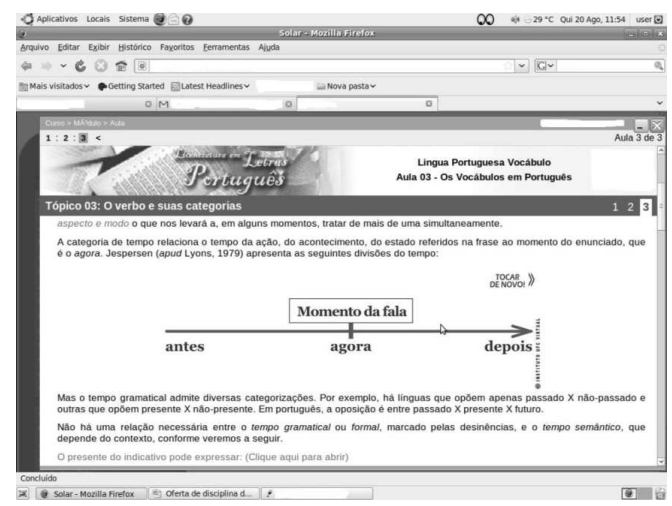


João relatou que lê os materiais em momento oportuno, alguns dias após a impressão. "Em casa não tem outras coisas, [não fico] usando web sites, fazendo outras atividades, assim não se concentra. Em casa me volto mais para o texto [impresso]". Ele lê os conteúdos tendo sobre a mesa outros livros relacionados à temática (dicionários e livros acadêmicos). A leitura do texto principal desencadeia uma espécie de estímulo para ir às fontes e João movimenta-se entre esse material e os outros livros, em geral buscando esclarecer e aprofundar elementos relacionados à temática da disciplina em curso. Em geral, faz grifos no material e insere anotações nas margens do texto principal, com dados que colhe em outros livros. Não há uma sequência padrão. João consulta os livros diversas vezes durante uma sessão de estudos. Ele diz que faz anotações à mão no material impresso a fim de organizar o conteúdo porque "assim fica melhor para estudar para a prova".

Ao realizar leituras dos conteúdos no material impresso, João retorna ao conteúdo digital da "Aula", no AVA. Isso, em geral, ocorre nos finais de semana, quando tem acesso discado à internet em sua residência. Ele assiste a um mesmo vídeo duas ou três vezes, acessa algumas animações e textos indicados via web links na "Aula".

A seguinte experiência é representativa da centralidade do material impresso no processo de aprendizagem do aluno. O conteúdo na "Aula" traz uma atividade no formato de quiz, em que o aluno pode digitar respostas e obter confirmações de "certo" ou "errado" na tela, em tempo real. No entanto, João imprimiu essa atividade, escreveu as respostas no papel e só então digitou as respostas no quiz digital no AVA.

\section{Estrutura e coesão do artefato semiótico}

Lemke (2001) propõe 76 “questões” para a análise semiótica de artefatos hipermodais, distribuídas em três categorias estáveis: organização e significação (coesão e estrutura), apresentação (formas de representação) e orientação (sociointerativo). $\mathrm{O}$ autor afirma ter formulado tais categorias a fim de focar a atenção dos analistas em uma variedade de tipos significativos e funções voltadas à análise de artefatos semióticos multimodais. Devido às limitações de espaço deste trabalho, apresento uma análise baseada em algumas questões da primeira categoria formula- 
da pelo autor. O mapeamento dos elementos de estrutura e coesão dos conteúdos da "Aula" faz-se necessário a partir das considerações de McEneaney (2000), ao argumentar que

a simples exposição dos alunos a conteúdos hipertextuais pode confundi-los
e frustrá-los. Mas ao se impor trilhas também estaremos limitando as formas
pelas quais os alunos podem explorar e aprender a partir dos conteúdos dis-
ponibilizados. A questão está em se ter mais clareza se o suporte oferecido [a
estrutura e a coesão do conteúdo] colabora ou prejudica a aprendizagem
(MCENEANEY, 2000 , p. 2 , tradução nossa).

Como detalhado no Quadro 1, percebe-se a presença dos elementos de estrutura e coesão semiótica dos conteúdos hipermodais. Por exemplo, elementos de cor, padronização de fontes, ícones e cabeçalhos indicam claramente as partes constituintes e as fronteiras espaciais do material, a fim de organizar e dar sentido aos conteúdos e à navegação dos alunos. Os elementos de organização mantêm, dessa forma, a possibilidade de que o aluno possa recuperar facilmente seu percurso, seu trajeto realizado no material de estudo (LEÃO, 2001).

Porém, ao se documentar a navegação e o uso desses artefatos pelos alunos para fins de aprendizagem, verifica-se uma ruptura com tais categorias, como demonstra a experiência de João. Essa ocorrência foi antecipada, em parte, por Lemke, ao reconhecer que "leitores exploram rotas alternativas através do hipertexto, ou criam suas próprias transversais" (2002, p. 322, tradução nossa), sem, no entanto, contemplar a possibilidade de rotas para além dos conteúdos hipermodais e da tela do computador, como no uso do material impresso realizado por João. 


\section{Quadro 1. Análise das categorias estáveis do artefato semiótico.}

\begin{tabular}{c} 
“QUESTÕES" PARA \\
ANÁLISE SEMIÓTICA \\
(LEMKE, 2001, \\
tradução nossa) \\
\hline Como se sabe o que é parte \\
dele e o que não é parte \\
dele? Possui uma fronteira ou \\
moldura definida no espaço?
\end{tabular}

Percebe-se a estrutura de parágrafos de textos intermediados por elementos iconográficos (imagens, animações, vídeos) e coesão (padrões de cor, caixas e fonte textual destacados), possuindo função organizacional. Conjunto de páginas numeradas e visualmente padronizadas intituladas "Aulas" e organizadas sequencialmente (1, 2, 3, etc.), contendo texto escrito, ícones, figuras, animações, web links e vídeos.

\begin{tabular}{|c|c|c|}
\hline $\begin{array}{l}\text { Quais as mais longas cadeias } \\
\text { de elementos - na base da } \\
\text { similaridade ou de links } \\
\text { visuais a partir de estrutura } \\
\text { mais ampla (relação } \\
\text { geométrica espacial, links } \\
\text { gráficos)? }\end{array}$ & $\begin{array}{l}\text { Percebe-se as páginas sequenciais }(1,2,3 \text {, } \\
\text { etc.) da "Aula", destacadas em caixa } \\
\text { superior, com cor e fonte de texto padrão. } \\
\text { Dentro delas há web links de nível primário } \\
\text { que criam relação estrutural de expansão- } \\
\text { elaboraçãa com o texto principal. }\end{array}$ & $\begin{array}{l}\text { Alunos extrapolaram as sequências, as lon- } \\
\text { gas cadeias de elementos e as } \\
\text { fronteiras espaciais formais, acessando } \\
\text { outras áreas dentro do AVA, mas fora da } \\
\text { "Aula". A partir dessas áreas, } \\
\text { acessam web links fora do AVA. } \\
\text { Todos os conteúdos acessados } \\
\text { tornam-se material hipermodal utilizado } \\
\text { para a aprendizagem. }\end{array}$ \\
\hline $\begin{array}{l}\text { Que tipo de relação de } \\
\text { sentido isso cria? }\end{array}$ & $\begin{array}{l}\text { Percebe-se uma unidade de conteúdos que } \\
\text { progridem em tópicos ao longo de uma } \\
\text { sequência estruturada, entremeada por ele- } \\
\text { mentos hipermodais. A coesão é construída } \\
\text { por cor e fonte textual padrão. Os links } \\
\text { inseridos e os } \\
\text { elementos iconográficos demandam a } \\
\text { atenção e a ação do usuário. }\end{array}$ & $\begin{array}{l}\text { Altera-se, portanto, o sentido da } \\
\text { coesão semiótica a partir da ação da } \\
\text { pragmática de busca de informações } \\
\text { e realização de atividades vistas } \\
\text { como imprescindíveis para a atividade de } \\
\text { aprendizagem. }\end{array}$ \\
\hline $\begin{array}{l}\text { Qual o elemento visual } \\
\text { mais saliente? }\end{array}$ & Cor & Texto \\
\hline $\begin{array}{l}\text { Como os vetores são } \\
\text { definidos graficamente } \\
\text { em termos de trilhas e } \\
\text { direcionalidade? }\end{array}$ & $\begin{array}{l}\text { 1. Cor } \\
\text { 2. Números }\end{array}$ & $\begin{array}{l}\text { Alterna-se entre o fluxo linear do texto } \\
\text { impresso, com leitura da esquerda para a } \\
\text { direita, e diversas interrupções (saltos) para } \\
\text { consulta a outros materiais impressos e } \\
\text { hipermodais. }\end{array}$ \\
\hline $\begin{array}{l}\text { Como o texto é associado a } \\
\text { outros elementos visuais? }\end{array}$ & $\begin{array}{l}\text { Percebe-se que elementos visuais atuam } \\
\text { como uma ilustração dos textos (em geral } \\
\text { sem interferir com as informações textuais) } \\
\text { ou para conectar blocos de textos (nesse } \\
\text { caso, podendo interferir com as informações } \\
\text { textuais, apresentando exemplos, dados } \\
\text { mais aprofundados, etc.). }\end{array}$ & $\begin{array}{l}0 \text { texto escrito se sobrepõe aos outros ele- } \\
\text { mentos visuais e hipertextuais. }\end{array}$ \\
\hline $\begin{array}{c}\text { Para onde } 0 \text { olhar é } \\
\text { direcionado inicialmente? }\end{array}$ & $\begin{array}{l}\text { 1. Textos escritos } \\
\text { 2. Animações }\end{array}$ & $\begin{array}{c}\text { Ao acessarem a "Aula", alunos fazem a } \\
\text { leitura rápida (skimming) dos conteúdos e, } \\
\text { em seguida, realizam a impressão dos } \\
\text { materiais. }\end{array}$ \\
\hline
\end{tabular}

Alunos fazem a leitura rápida da tela (skimming) e acionam o comando "texto para impressão". Enquanto aguardam a geração do artigo PDF para impressão, alunos navegam em outras janelas, variando entre web sites de informação e entretenimento, e-mail, etc., e outros espaços do AVA, como fórum e mensagens.

USO 
A análise apresentada no Quadro 1 indica que o design dos conteúdos da "Aula" constitui-se a partir dos princípios do livro eletrônico, com uma estrutura arborescente (LEÃO, 2001), em que o texto central representa o núcleo (o tronco de uma árvore) ao qual estão conectados os demais elementos (os galhos e as folhas), como os web links, as imagens, os vídeos, indicando a reprodução digital do paradigma do livro acadêmico. Configuram-se, portanto, como hipertextos exploratórios, em que "o leitor preservaria o conteúdo proposto pelo autor e apenas selecionaria trilhas, roteiros ou opções de leitura previstas imanentemente pelo autor do hipertexto" (MARCUSCHI, 2005, p. 191). A experiência do uso, no entanto, indica outras possibilidades, analisadas mais detidamente a seguir.

\section{Práticas comunicativas}

Kress (2003, p. 162, tradução nossa) acredita ser "simplesmente impossível esperarmos que jovens leiam da maneira antiga, a não ser em maneiras específicas de aprendizagem, em casos em que razões claras serão necessárias para justificar tal diferença e os propósitos de tal manutenção". O autor descreve processos que se assemelham, em alguns aspectos, às práticas dos alunos, como as de João, entre eles a leitura inicial (scanning), a identificação do modo dominante (o impresso) e a possibilidade de integração de modos não-dominantes (elementos hipermodais) ao dominante, ou de tratá-los igualmente e lê-los conjuntamente. Segundo Kress, o leitor também poderá avaliar a função de cada modo no nível da estrutura (complementar ou suplementar) e seu papel especializado (textos com função pedagógica e imagens com conteúdo curricular ou vice-versa). A percepção e a compreensão sobre tais elementos, diz o autor, dará origem a uma estratégia para leitura do texto multimodal.

As teorizações de Kress permitem compreender o deslocamento, operado por João, do foco principal de suas atividades de estudo da tela do computador para a "apostila" e os livros - em detrimento dos conteúdos curriculares disponibilizados. Nos materiais impressos, por sua vez, predomina o texto escrito. Elementos hipermodais assumem função pedagógica, na medida em que João os relega a um segundo plano de atenção e leitura, assumindo função suplementar, ilustrativa. 
A experiência de João indica que isso se dá, porém, não pela construção semiótica dos conteúdos - que apresentam estrutura e coesão -, mas a partir da cultura e das intenções dos alunos. Isso significa que a valorização de conteúdos impressos para o estudo situa-se a partir das condições socioculturais de uso dos conteúdos curriculares e do objetivo dos alunos de obter sucesso nas avaliações formais do curso.

Hanks (1996) permite estender alguns aspectos das formulações de Kress e de nossa análise, ao buscar compreender as práticas comunicativas como ponto de convergência de três esferas:

- a linguagem como sistema semiformal regido por regras, mas não de todo submetido a elas;

- as atividades comunicativas como processos semiestruturados que se definem em ações mediadas pelo contexto;

- e a contemplação reflexiva dos valores socioculturais, a avaliação dos atores sobre a linguagem e do contexto com base em valores, crenças e atitudes autolegitimadoras.

Essas três esferas permitem a Hanks (1996, p. 233, tradução nossa) propor que "aspectos emergentes" se constituem em oposição aos "aspectos esquemáticos" formais da linguagem. Para o autor, os aspectos emergentes referem-se "àqueles elementos da prática que emergem ao longo do curso da ação, como parte da ação. Aspectos emergentes não são dados aos agentes a priori de seu engajamento e portanto não são nem pré-fabricados nem estáveis. Eles se constituem em processo".

Tais proposições nos permitem compreender a flexibilidade de sentidos dos artefatos e conteúdos hipermodais a partir da compreensão das atividades comunicativas (as práticas), que envolvem o uso desses materiais, como processos semiestruturados, sujeitos à avaliação dos atores, que o fazem com base em sua cultura (a partir de valores, crenças e atitudes autolegitimadoras) e intenções.

\section{Conexões entre o impresso e o hipermodal}

A leitura do texto impresso em detrimento da leitura em tela do computador, como no caso de João, não é uma ocorrência nova. Estudos já demonstraram que a velocidade de leitura na tela chega a ser $30 \%$ menor do que a de textos impressos e que o texto na tela pode ter reso- 
lução até dez vezes inferior ao texto impresso de boa qualidade (de 110 dpi para 1.200 dpi, respectivamente) (ALMEIDA, 2003).

Há que se considerar também que alunos como João, que imprimem os conteúdos hipertextuais para "melhor estudar", referem-se a experiências de educação formal passadas e presentes que ainda associam o saber a conteúdos impressos. Ponzio (1993 citado por SANTAELLA, 2004 , p. 168) esclarece tal deslocamento da tela para o impresso ao propor que "o sentido não subsiste no seu próprio contexto, no seu tempo presente, mas também em relação a um dado passado, uma tradição à qual ele pertence, uma esfera muito mais ampla do que aquela que é referida por habilidades interpretativas imediatas dos interlocutores e seus contemporâneos".

Outro fator associado, ilustrado pelas práticas de João, refere-se às condições objetivas relacionadas à baixa renda econômica desses alunos, com destaque ao limitado acesso às tecnologias digitais. Observa-se que, muitas vezes, não há computadores em número suficiente nos pólos presenciais de ensino ligados à $\mathrm{UAB}$ para atender a todos os alunos, a internet funciona debilmente em algumas situações e não há possibilidade de imprimir materiais. No entanto, alunos que relatam ter adquirido um computador pessoal "para estudar", como João, (ainda) preservam a centralidade dos conteúdos impressos.

Mais significativos, no caso desse estudo, parecem ser os processos de hibridação e de expansão dos conteúdos hipermodais articulados pelos alunos. Primeiro, configura-se uma espécie de continuum (LÉVY, 1993; CHARTIER, 1998) entre o "i-texto (texto impresso) e e-texto (texto eletrônico)" (MARCUSCHI, 2005, grifo do autor, p. 204), pontuado, no entanto, pelo fato de João e outros alunos estabelecerem a centralidade do impresso e relegarem a um segundo plano, sem promover uma ruptura, os conteúdos multimodais em suas práticas de aprendizagem.

Segundo, apresenta-se uma sistemática de navegação típica do hipertexto, cuja centralidade estabelece-se no impresso. Aarseth (1993 citado por LEÃO, 2001, p. 62), por sua vez, indica a possibilidade do "salto" (jump) como característica definidora do hipertexto em relação a textos tradicionais. Para o autor, isso permite uma leitura descontínua e o deslocamento quase instantâneo. A prática de navegação e leitura de João com o material impresso também contemplou diversos saltos, de modo semelhante ao operado com os conteúdos hipertextuais. 
O referido continuum, instituído nas práticas de João, comporta, portanto, uma não-linearidade marcada por uma multiplicidade de saltos, conexões e entrelaçamentos - semelhante a uma "rede" - na navegação e na leitura dos materiais impressos, dos conteúdos disponibilizados no AVA e outros materiais de escolha que o aluno julga diretamente relacionados aos conteúdos curriculares (ver Figura 3).

Figura 3. Representação da estrutura da "rede" de navegação e leitura de João, partindo e conferindo ênfase principal aos materiais impressos e suas conexões (links mais densos), seguidos pela ênfase secundária nos materiais multimodais da "Aula" e, por fim, os conteúdos da Internet.

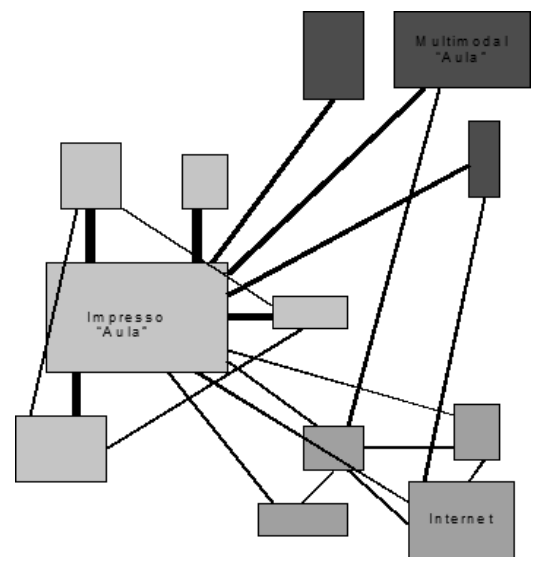

João "saltava" do texto-base impresso para consultar um dicionário e dali seguia para um livro acadêmico, para retornar ao dicionário e então ao texto-base e assim sucessivamente. Em suas práticas de aprendizagem como aluno a distância, ele se valeu da possibilidade do "salto", utilizando prioritariamente materiais impressos, e estabeleceu uma estrutura de navegação e leitura articulada em três níveis associados. No primeiro nível, foco de maior atenção e interesse de João, situam-se os materiais impressos - o conteúdo disponibilizado pela instituição, os livros de estudo escolhidos pelo aluno (muitos retirados na biblioteca da instituição ou emprestado por colegas) e outros materiais impressos da internet. No segundo nível estão os elementos multimodais disponibilizados pela instituição, animações, vídeos e web links, visualizados pelo aluno na tela do computador. E em terceiro nível encontram-se elementos multimodais pesquisados na internet pelo aluno. A coesão temática agrega todos esses materiais em uma arquitetura maleável de "rede", que possui ponto de 
partida definido mas que não está totalmente fechada - há abertura tanto para outros materiais impressos quanto para outros conteúdos hipermodais, ainda que isso não defina sua tônica.

Isso indica que as práticas e a cultura que amparam o uso que os alunos fazem do conteúdo hipermodal, inicialmente disponibilizado pela instituição de ensino, introduzem mudanças nos elementos semióticos que os constitui, interferindo nas saliências, na estrutura e na coesão de elementos-chave do conteúdo, e abrem a possibilidade de estabelecimento de novas redes de navegação e leitura dos materiais amealhados pelo aluno a partir da temática de estudo. Tais ocorrências independem da qualidade da estrutura e da coesão dos conteúdos do artefato semiótico, como demonstrado no Quadro 1. Como apontando por Ribeiro (2005, p. 131), ao referir-se aos usos do hipertexto, "o leitor acaba por chegar a uma nova forma de manipular (navegar!) o objeto novo, que passa, então, a fazer parte de um universo de possibilidades que jamais será fechado", ainda que delimitado pelas possibilidades, interesses e objetivos do leitor. Nesse caso, alunos de EaD, em busca de uma melhor compreensão dos conteúdos, com vistas a obter sucesso nas avaliações formais do curso.

Ainda que centrado no impresso, o uso dos conteúdos por João contempla ações de navegação hipertextual e preserva os elementos de hibridização de linguagens e processos sígnicos integrados, características do hipertexto. Dessa forma, no que tange a navegação, as ações de João nos permitem aproximá-lo do perfil do internauta previdente proposto por Santaella (2004), e extrapolá-lo. João não internalizou apenas as regras da navegação, como propõe a autora, mas também as regras de busca e leitura de conteúdos para a aprendizagem e, portanto, "executa procedimentos navegacionais condizentes com a regras" (SANTAELLA, 2004, p. 118). Isso resulta em certo afastamento de práticas características do usuário errante (SANTAELLA, 2004), relegando práticas de navegação dispersivas, imprevisíveis, caóticas (ENTLER, 2002) a um nível inferior de importância. João guia-se pelo fim pragmático da aprendizagem, reconstruindo coerência a partir de critérios de relevância em meio a um "mix discursivo" (MARCUSCHI, 2005, p. 187) e, assim, aproxima-se da figura ideal do leitor imersivo proposto por Santaella.

Pode-se articular que o aluno foi bem-sucedido em sua prática com conteúdos hipermodais a partir da proposição de Cope e Kalantzis (2000) de que 
a compreensão multimodal é muito mais do que a soma dos modos da linguagem, do visual, espacial, gestual. Envolve também processo de integração e de maior ou menor ênfase entre os vários modos. No centro do processo de integração estabelece-se a "multiplicidade" inerente da expressão e da percepção humana, a sinestesia. (COPE; KALANTZIS, 2000, p. 211, tradução nossa)

Emprestando uma expressão de Chartier, João produziu a "dessacralização" (1998, p. 88) do conteúdo hipermodal ao instituir a centralidade do material impresso, suporte em que intervém para os fins almejados, considerando condições contextuais. João inscreveu sua escrita nas margens dos textos (o que não é possível fazer no conteúdo das "Aulas"), ainda que isso tenha constituído uma ação periférica em relação à autoridade do conteúdo estruturado e coeso da instituição de ensino.

\section{Conclusão}

A partir o referencial teórico de Hanks sobre as práticas comunicativas, a análise da evidência empírica indica a necessidade da flexibilização das formas estáveis propostas por Lemke. A formulação de conteúdos hipermodais mais flexíveis dá-se em linha com atividades comunicativas articuladas em dado contexto e mediadas por valores socioculturais dos alunos. Afinal, como Lemke (2002, p. 322) reconhece, "a hipertextualidade convida e possibilita cadeias de ofertas e demandas dialógicas mais complexas [...] entre usuários e designers e web sites [...] do que textos construídos com a forte expectativa de que os leitores sigam uma sequência pré-determinada".

Torna-se importante evitar, portanto, experiências apontadas por Hanks (1996, p. 8) em que "primeiro definimos formas e só então adicionamos uma camada de contexto. Somente combinando essa duas instâncias poderemos atingir significados complexos".

Estabelece-se, dessa forma, a necessidade de compreendermos e desenharmos os artefatos e conteúdos hipermodais em sua interpenetração com as experiências dos atores sociais, ou seja, o "engajamento prático" (HANKS, 1996, p. 130) deles com os artefatos - marcadamente quando esses se destinam a processos de aprendizagem formal. Nesses casos, configura-se um uso (navegação e leitura), um "modo de acesso" interpre- 
tativo (MARCUSCHI, 2005, p. 202) orientado pela busca de coerência do usuário que extrapola a dicotomia impresso/digital. Tal perspectiva nos permite compreender, parafraseando Hanks, não o que poderiam significar as experiências dos alunos com o uso de tais artefatos e conteúdos hipermodais, mas o que de fato significam em certas condições.

Santaella (2004, p. 52) nos indica que

quanto maior a interatividade, mais profunda será a experiência de imersão do leitor, imersão que se expressa na sua concentração, atenção, compreensão da informação e na sua interação instantânea e contínua com a volatilidade de estímulos. O desenho da interface [e dos conteúdos] é feito para incentivar a determinação e a tomada de decisão por parte do usuário.

Coloca-se, dessa forma, a necessidade de se estabelecer processos de design participativo, em que usuários-alunos possam cooperar, abrindo-se a possibilidade de disponibilização de conteúdos cada vez mais interativos e democráticos. Isso poderá ampliar as possibilidades da mediação pedagógica (GUTIERREZ; PIETRO, 1991) desses conteúdos (uso centrado no aluno), resultando em ganhos significativos a tais processos de aprendizagem. 


\section{Referências}

ALMEIDA, Rubens. O leitor navegador (II). In: SILVA, Ezequiel (Coord.). A leitura nos oceanos da internet. São Paulo: Cortez, 2003.

BOGDAN, Robert; BIKLEN, Sari. Qualitative research for education. 4 ed. New York: Allyn and Bacon, 2003.

CHARTIER, Roger. A aventura do livro. Do leitor ao navegador. São Paulo: Editora Unesp, 1998.

COPE, Bill; KALANTZIS, Mary. Designs for social futures. In: COPE, B.; KALANTZIS, M. (Eds.) Multiliteracies. Literacy learning and the design of social futures. New York: Routledge, 2000.

ENTLER, Ronaldo. O caos e a teia: potenciais revelados na complexidade da internet. 2002. Disponível em <http://www.entler.com.br/textos/caos_teia.html>. Acesso em: 20 Out. 2009.

FAIRCLOUGH, Norman. Multiliteracies and language. Orders of discourse and intertextuality. In: COPE, B. e KALAZANTZIS, M. (Eds.) Multiliteracies. Literacy learning and the design of social futures. New York: Routledge, 2000.

GUTIERREZ, Francisco; PRIETO, Daniel. A mediação pedagógica: Educação à Distância alternativa. Campinas: Papirus, 1991.

HANKS, William. Language and communicative practices. Boulder, CO. Westview Press, 1996. JUNQUEIRA, Eduardo S. Challenging the boundaries between standard and popular language situated in historical contexts: The communicative practices of high-school Brazilian students crafting hybrid multi-modal ways with words. Language and Education, v. 22, p. 393, 2008.

KRESS, Gunther. Literacy in the new age. London: Routledge, 2003.

LEÃO, Lucia. O labirinto da hipermídia. 2 ed. São Paulo: Iluminuras, 2001

LEMKE, Jay. Multimedia semiotic analysis - Focal questions. 2001. Disponível em <http://www-personal.umich.edu/ jaylemke/guides/multimedia_semiotic_analysis_ questions.htm>. Acesso em: 16 Out., 2009.

LEMKE, Jay. Travels in hypermodality. Visual Communication, v. 1, n. 3, 2002.

McENEANY, John E. Visualizing and assessing navigation in hypertext. In: Proceedings of the tenth ACM conference on hypertext and hypermedia: Returning to our diverse roots (pp. 6170). New York: Association for Computing Machinery, 1999. Disponível em: http://www.acm.org.pubs/citations/proceedings/hypertext/294469/p61-mceneaney/. Acesso em: 28 Jun. 2009.

MARCUSCHI, Luiz Antônio. A coerência no hipertexto. In: COSCARELLI, Carla V. e RIBEIRO, Ana Elisa. Letramento digital. Aspectos sociais e possibilidades pedagógicas. Belo Horizonte: Autêntica, 2005.

RIBEIRO, Ana Elisa. Ler na tela - letramento e novos suportes de leitura e escrita. In: COSCARELLI, Carla V.; RIBEIRO, Ana Elisa. Letramento digital. Aspectos sociais e possibilidades pedagógicas. Belo Horizonte: Autêntica, 2005.

SANTAELLA, Lucia. Navegar no ciberespaço: o perfil cognitivo do leitor imersivo. São Paulo: Paulus, 2004. 


\section{Notas}

${ }^{1}$ Em trabalho anterior (JUNQUEIRA, 2008), delineei o conceito de multimodalidade a partir de Fairclough (2000, p. 171), para o qual multimodalidade refere-se "à crescente saliência de múltiplos modos de significação - linguística, visual, auditiva e outras, e a crescente tendência dos textos se tornarem multimodais".

Recebido: 06/11/2009

Aprovado: $30 / 07 / 2010$

Contato:

Universidade Federal do Ceará Instituto UFC Virtual

Campus do Pici Bloco 901 ( $1^{\circ}$ andar do prédio NPD) Pici

Fortaleza - CE

CEP 60455-760 